\section{(Wild)fire is not an ecosystem service}

In their paper entitled "Wildfires as an ecosystem service", Pausas and Keeley (2019) summarize the benefits generated by - as well as the evolutionary and socioecological importance of - wildfires for humankind. Although we recognize the importance of wildfires in such a context, we argue that presenting wildfire per se as an ecosystem service is conceptually incorrect and can be misleading for policy makers and resource managers. Throughout their paper, the authors repeatedly refer to (wild)fire as a potential provider of multiple ecosystem services (and not as an ecosystem service itself, as indicated in their article's title). We believe that this is more than a dispute over semantics, for such a contradiction could lead to misperceptions about the definition of the term "ecosystem services", which is especially concerning in light of its realworld applications to fire management.

Incorporating (wild)fire into the broader conceptual framework of ecosystem services is problematic for a number of reasons, starting with the negative assumption of "wildfire" as an unplanned event with undesired societal or environmental impacts, and given that wildfire includes both services and disservices (Vaz et al. 2017). We argue that using the term "fire" (as often done by Pausas and Keeley) instead of "wildfire" emphasizes the process itself (Bowman et al. 2009) and thereby enables a more balanced perspective of its positive and negative contributions to human well-being (Costanza et al. 2017; Vaz et al. 2017). The ecosystem services cascade model (Potschin and Haines-Young 2016) helped to distinguish between ecosystem structures, processes, functions, services, benefits, and values. Here, ecosystem services refer to the positive - not the negative - contributions of ecosystems to human wellbeing, connecting the ecological and the social dimensions of socioecological systems. The capacity of each ecosystem (that is, its function) to provide services and benefits to society is influenced by interactions between processes (such as fire) and biophysical structures (such as vegetation) (Potschin and Haines-Young 2016; Costanza et al. 2017; Pettorelli et al. 2018). Conversely, losses in the regulating services of an ecosystem may jeopardize that system's ability to deliver provisioning services in the future (Sil et al. 2019).

As an ecological process, fire not only is part of a complex network of interactions that shape ecosystem functioning (Bowman et al. 2009) but also is shaped by management actions and people's perceptions that affect an ecosystem's (in)ability to regulate fire (Silva et al. 2010), which in turn shapes the positive or negative impacts of fire on human well-being and how society views fire (Sil et al. 2019). The Common International Classification of Ecosystem Services (Haines-Young and Potschin 2018) recognizes "fire protection" as an ecosystem service. In the above-mentioned cascade model, an ecosystem's fire regulation capacity allows maintaining fire-regime attributes (eg fire frequency and severity) within "safe" boundaries (Sil et al. 2019), alongside other ecosystem services. Pausas and Keeley (2019) provide many valuable examples of such services, but largely overlook the negative outcomes of fire to humans (ie disservices; see below) (Figure 1 and WebTable 1), which contributes to an unbalanced perspective of
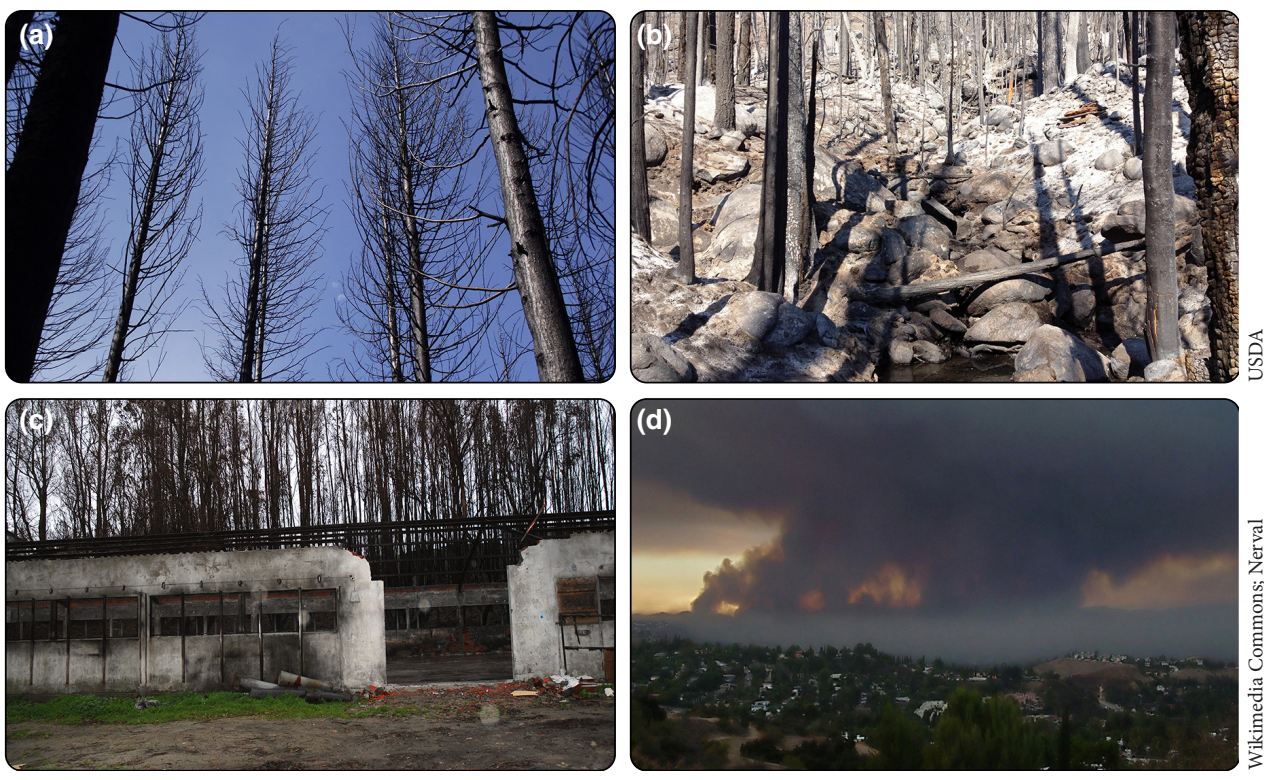

Figure 1. Fire negatively affects ecosystem services such as (a) wood production (provisioning service) and (b) erosion control (regulating service) and acts as a source of ecosystem disservices including (c) destruction of infrastructure (material disservice) and (d) air pollution (health disservice). 
tem services, their use of the term in their paper's title is potentially misleading. Failing to integrate fire as an ecological process within an ecosystem services-disservices framework can promote a biased perspective of wildfire. An example of the risks of such a perspective is the historical fire-suppression policy that largely ignored the various socioecological roles of fire, indirectly fostering catastrophic fires over the past decades (the so-called "Fire Paradox"; Silva et al. 2010). Improved communication of ecosystem services and disservices can help to guide decision making in fire management policy and land-use planning.

\section{- Acknowledgements}

ÂS received support from the Portuguese Foundation for Science and Technology (FCT) through $\mathrm{PhD}$ grant SFRH/BD/ $132838 / 2017$, funded by the Ministry of Science, Technology and Higher Education, and by the European Social Fund-Operational Program Human Capital within the 2014-2020 EU Strategic Framework. AR is funded by Xunta de Galicia (post-doctoral fellowship ED481B2016/084-0). This research was developed as part of the project FirESmart (PCIF/MOG/0083/2017), which received funding from the FCT. The authors declare that they have no conflicts of interest.

\author{
Ângelo Sil ${ }^{1,2,3,4 *}$, João C Azevedo ${ }^{4}$, \\ Paulo M Fernandes ${ }^{3}$, Adrián Regos ${ }^{1,5}$, \\ Ana Sofia $\mathrm{Vaz}^{1,6,7}$, and \\ João P Honrado, ${ }^{1,2}$ \\ ${ }^{1}$ InBIO/Centro de Investigação em \\ Biodiversidade e Recursos Genéticos \\ (CIBIO), Campus Agrário de Vairão, \\ Vairão, Portugal *(angelosil@cibio.up.pt); \\ ${ }^{2}$ Faculdade de Ciências da Universidade \\ do Porto, Porto, Portugal; ${ }^{3}$ Centro de \\ Investigação e de Tecnologias Agro- \\ Ambientais e Biológicas (CITAB), \\ Universidade de Trás-os-Montes e Alto \\ Douro, Vila Real, Portugal; ${ }^{4}$ Centro de \\ Investigação de Montanha (CIMO), \\ Instituto Politécnico de Bragança, \\ Campus de Santa Apolónia, Bragança, \\ Portugal; ${ }^{5}$ Departamento de Zooloxía,
}

Xenética e Antropoloxía Física,

Universidade de Santiago de Compostela, Campus Sur, Santiago de Compostela, Spain; ${ }^{6}$ Laboratorio de Ecología (iEcolab), Instituto Interuniversitario de Investigación del Sistema Tierra en Andalucía (IISTA-CEAMA), Universidad de Granada, Granada, Spain; ${ }^{7}$ Departamento de Botanica, Universidad de Granada, Facultad de Ciencias, Campus Fuentenueva,

Granada, Spain

Abson DJ, Von Wehrden H, Baumgärtner S, et al. 2014. Ecosystem services as a boundary object for sustainability. Ecol Econ 103: 29-37.

Adams MA. 2013. Mega-fires, tipping points and ecosystem services: managing forests and woodlands in an uncertain future. Forest Ecol Manage 294: 250-61.

Bowman DMJS, Balch JK, Artaxo P, et al. 2009. Fire in the Earth system. Science 324: 481.

Costanza R, De Groot R, Braat L, et al. 2017. Twenty years of ecosystem services: how far have we come and how far do we still need to go? Ecosystem Services 28: $1-16$.

Haines-Young R and Potschin M. 2018. Common International Classification of Ecosystem Services (CICES) V5.1 and Guidance on the Application of the Revised Structure. https://bit.ly/2ZKcKOU. Viewed 20 May 2019.

Keeley JE, Baer-Keeley M, and Fotheringham CJ. 2005. Alien plant dynamics following fire in Mediterranean-climate California shrublands. Ecol Appl 15: 2109-25.

Pausas JG and Keeley JE. 2019. Wildfires as an ecosystem service. Front Ecol Environ 17: 289-95.

Pettorelli N, Schulte to BühneH, Tulloch A, et al. 2018. Satellite remote sensing of ecosystem functions: opportunities, challenges and way forward. Remote Sens Ecol Conserv 4: 71-93.

Potschin M and Haines-Young R. 2016. Conceptual frameworks and the cascade model. In: Potschin M and Jax K. (Eds). OpenNESS Ecosystem Services Reference Book. EC FP7 Grant Agreement no 308428. www.openness-project.eu/library/refer ence-book. Viewed 20 May 2019.

Sil Â, Fernandes PM, Rodrigues AP, et al. 2019. Farmland abandonment decreases the fire regulation capacity and the fire protection ecosystem service in mountain landscapes. Ecosystem Services 36: 100908.
Silva JS, Rego F, Fernandes P, and Rigolet E (Eds). 2010. Towards integrated fire management - outcomes of the European project Fire Paradox. Research report 23. Joensuu, Finland: European Forest Institute.

Vaz AS, Kueffer C, Kull CA, et al. 2017. Integrating ecosystem services and disservices: insights from plant invasions. Ecosystem Services 23: 94-107.

\section{Supporting Information}

Additional, web-only material may be found in the online version of this article at http://onlinelibrary.wiley.com/ doi/10.1002/fee.2106/suppinfo

\section{Wildfires misunderstood}

Rain is a natural process that provides a range of services to humans but certainly not all rainfall events (eg those generating floods) are beneficial to human societies. Biodiversity can also deliver a variety of services, even though there are species capable of harming humans. Likewise, the vast majority of life depends (directly or indirectly) on sunlight, yet we can get sunburn and develop skin cancer after overexposure. In the same way, wildfires can offer a range of ecosystem services (Pausas and Keeley 2019) but obviously not all fires, and not all fire regimes, provide services to humankind; indeed, wildfires can have negative (even catastrophic) impacts on society. For instance, if we build houses in a fire-prone (or flood-prone) area, then the inhabitants of those houses are likely to suffer negative impacts when a wildfire (or a major rainfall event) occurs. Similarly, when we substantially increase fuel loads and landscape homogeneity (eg due to a fire exclusion policy, or with a massive and poorly managed tree plantation), the impact of wildfires - especially under novel climatic conditions - can be catastrophic (eg the case of the 2017 fires in Portugal and Chile; Bowman et al. 2019).

In more general terms, negative impacts to humans (disservices) often occur when we perturb the historical fire regime: that is, when one or some of the fire regime parameters (ie frequency, seasonality, spread pattern, or intensity) are altered 